\title{
Current Directions in Psychological Science \\ http://cdp.sagepub.com/
}

\section{Different Bodies, Different Minds : The Body Specificity of Language and Thought Daniel Casasanto \\ Current Directions in Psychological Science 2011 20: 378 \\ DOI: $10.1177 / 0963721411422058$}

The online version of this article can be found at:

http://cdp.sagepub.com/content/20/6/378

\section{Published by:}

(\$)SAGE

http://www.sagepublications.com

On behalf of:

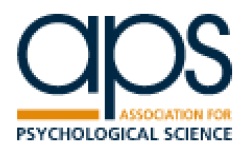

Association for Psychological Science

Additional services and information for Current Directions in Psychological Science can be found at:

Email Alerts: http://cdp.sagepub.com/cgi/alerts

Subscriptions: http://cdp.sagepub.com/subscriptions

Reprints: http://www.sagepub.com/journalsReprints.nav

Permissions: http://www.sagepub.com/journalsPermissions.nav

>> Version of Record - Dec 5, 2011

What is This? 


\title{
Different Bodies, Different Minds: The Body Specificity of Language and Thought
}

Current Directions in Psychological Science

20(6) 378-383

(C) The Author(s) 201I

Reprints and permission: sagepub.com/journalsPermissions.nav DOI: 10.1 |77/096372|4||422058 http://cdps.sagepub.com

(\$SAGE

\section{Daniel Casasanto}

Department of Psychology, The New School for Social Research; Neurobiology of Language Department, Max Planck Institute for Psycholinguistics; and Donders Institute for Brain, Cognition, and Behaviour

\begin{abstract}
Do people with different kinds of bodies think differently? According to the body-specificity hypothesis (Casasanto, 2009), they should. In this article, I review evidence that right- and left-handers, who perform actions in systematically different ways, use correspondingly different areas of the brain for imagining actions and representing the meanings of action verbs. Beyond concrete actions, the way people use their hands also influences the way they represent abstract ideas with positive and negative emotional valence like "goodness," "honesty," and "intelligence" and how they communicate about these ideas in spontaneous speech and gesture. Changing how people use their right and left hands can cause them to think differently, suggesting that motoric differences between right- and left-handers are not merely correlated with cognitive differences. Bodyspecific patterns of motor experience shape the way we think, feel, communicate, and make decisions.
\end{abstract}

\section{Keywords}

body-specificity hypothesis, concepts, embodied cognition, handedness, hemispheric specialization, motor experience

What role does bodily experience play in constructing the mind? Since antiquity, a recurring answer has been: almost none. According to Plato, "the eyes, ears and the whole body, [are] a disturbing element, hindering the soul from the acquisition of knowledge" (from Phaedo, ca. 360 B.C.E.; Plato, 2010) Plato believed that before birth, we are endowed with perfect knowledge of everything. Bodily experience stimulates us to discover parts of our inborn knowledge (a view echoed by nativist theories of language and concepts in the 20th century; Chomsky, 1965; Fodor, 1998), but it also distorts this knowledge. Plato made a distinction between the distorted ideas that people actually use and perfect "essential" ideas, of which our ordinary thoughts are just shadowy reflections. Essential ideas are immutable and pure, whereas ordinary thoughts are constantly changing and are tainted by bodily experience.

In contemporary cognitive science, the difference between essential ideas and ordinary thoughts is echoed in the distinction between concepts and instantiations of these concepts (i.e., particular instances of activating a concept). Concepts are generally believed to be stable across time and across individuals (Machery, 2009; Prinz, 2002; cf., Barsalou, 1987). Instantiations may vary, but the concepts of which they are instances remain unchanged. Yet, despite widespread acceptance of this view, there is no empirical evidence that universal, invariant concepts exist. There is no evidence that an essential idea of "cat," or "game," or "happiness" is shared by all people at all times, or that our flexible thoughts are instantiations of invariant concepts.

On the other hand, there is abundant evidence that the patterns of neurocognitive activity that constitute our thoughts can vary dramatically from one instance to the next, and from one person to the next (Casasanto \& Lupyan, 2011). Arguably, these variable neurocognitive representations, which are always "contaminated" with physical and social experience, are all that we have. On this view, rather than instantiating preexisting concepts, we construct idiosyncratic neurocognitive representations ad hoc, activating stored information in response to the demands of the physical and social context.

Our bodies are an ever-present part of the context in which we use our minds, and should therefore exert a pervasive influence on the representations we tend to form. To the extent that the content of the mind depends on the structure of the body, people with different kinds of bodies should tend to think differently, in predictable ways. This is the body-specificity hypothesis (Casasanto, 2009). When people interact with the physical environment, their bodies constrain their perceptions and actions (e.g., Fischer, 2005; Linkenauger, Witt, Stefanucci, Bakdash, \& Proffitt, 2009). Here I review research

\section{Corresponding Author:}

Daniel Casasanto, Department of Psychology, The New School for Social Research, 80 Fifth Avenue, 7th Floor, New York, NY I00II

E-mail: casasanto@alum.mit.edu 
exploring ways in which the particulars of people's bodies also shape their words, thoughts, feelings, and choices.

\section{Body Specificity of Action Language and Motor Imagery}

Initial tests of the body-specificity hypothesis used handedness as a test bed. Right- and left-handers often perform the same actions differently. When people throw a ball, sign a check, or grasp a coffee mug, they usually use their dominant hand. Do differences in how people perform actions influence the way they imagine actions and process action language? To find out, my collaborators and I used functional magnetic resonance imaging (fMRI) to compare right- and lefthanders' brain activity during motor imagery and action-verb understanding.

\section{Imagined actions}

In one experiment, participants were asked to imagine performing actions while lying perfectly still in the fMRI scanner. They imagined some actions that are usually performed with the dominant hand (scribble, toss) and some actions performed with other parts of the body (kneel, giggle). Mental imagery for hand actions corresponded to different patterns of activity in right- and left-handers' motor systems. Left-hemisphere motor areas were activated in right-handers, but righthemisphere motor areas were activated in left-handers (Willems, Toni, Hagoort, \& Casasanto, 2009; Fig. 1). People with different kinds of bodies imagine the same actions differentlyin this case, using opposite hemispheres of the brain.

\section{Motor action and verb meaning}

A similar pattern was found when people read words for actions they usually perform with their dominant hands or

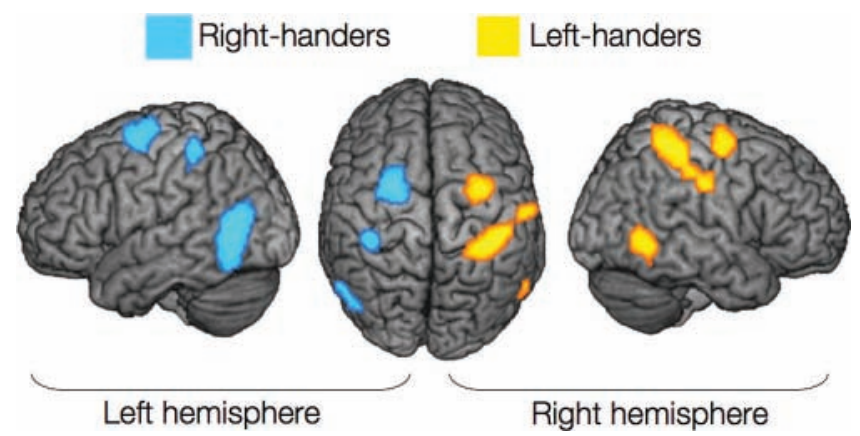

Fig. I. Neural activity in right-handers (blue) and left-handers (yellow) during motor imagery. These regions were more active when participants imagined hand actions than when they imagined actions performed with other parts of the body. Imagining hand actions activated brain areas responsible for planning and executing actions with the dominant hand, including parts of the precentral and postcentral sulci. For right-handers, this activity was found in the left hemisphere, which primarily controls actions with the right hand, but for left-handers it was found in the right hemisphere, which controls actions with the left hand. (Figure adapted from Willems et al., 2009.) with other parts of the body. When right-handers read words for hand actions, they activated the left premotor cortex, an area used in planning actions with the right hand. Left-handers showed the opposite pattern, activating right premotor areas used for planning left-hand actions (Willems, Hagoort, \& Casasanto, 2010). This was true even though they were not asked to imagine performing the actions or to think about the meanings of the verbs. Further fMRI experiments confirmed that activation during action-verb reading was not due to conscious imagery of actions (Willems, Toni, Hagoort, \& Casasanto, 2010).

Do the meanings of action verbs differ between right- and left-handers? One way to address this question is to determine whether the motor areas that show body-specific patterns of activation play a functional role in verb processing. We used theta-burst repetitive transcranial magnetic stimulation (rTMS) to modulate neural activity in the premotor hand areas identified in our earlier fMRI study. Participants' ability to distinguish meaningful manual action verbs from pseudowords was affected by rTMS to the premotor cortex in the hemisphere that controls their dominant hand, but not in the other hemisphere. rTMS to the hand areas had no effect on processing non-manual action verbs, which served as a control. These data suggest that when people read words like "grasp," neural activity in the premotor area that controls the dominant hand is not an epiphenomenon, or a downstream consequence of semantic processing. Rather, body-specific activation of the motor system plays a functional role in processing language about hand actions (Willems, Labruna, D'Esposito, Ivry, \& Casasanto, 2011). People tend to understand verbs as referring to actions they would perform with their particular bodiesnot to a Platonic ideal of the action or to the action as it is performed by the majority of language users. In this sense, people with different bodies understand the same verbs to mean something different.

\section{Body Specificity of Emotion}

Abstract concepts of things we can never perceive with the senses or act upon with the muscles are the hard case for any theory that foregrounds the role of bodily experience in constructing the mind. Beyond the concrete domain of action, how might bodily experience shape mental representations of more abstract ideas like goodness and badness, victory and loss, deceit and honesty? Like many abstract concepts, these notions carry either positive or negative emotional valence. Affective valence (i.e., positivity or negativity) and motivation (i.e., the predisposition to approach or withdraw from physical and social situations) appear to be grounded in patterns of body-specific motor experience.

\section{Choosing sides}

Across languages and cultures, good things are often associated with the right side of space and bad things with the left. 
This association is evident in positive and negative idioms like my right-hand man and two left feet, and in the meanings of English words derived from the Latin for "right" (dexter) and "left" (sinister).

Beyond language, people also conceptualize bad and good in terms of left-right space, but not always in the way linguistic and cultural conventions suggest. Rather, people's implicit associations between space and valence are body specific. When asked to decide which of two products to buy, which of two job applicants to hire, or which of two alien creatures looks more trustworthy, right- and left-handers respond differently. Right-handers tend to prefer the product, person, or creature presented on their right side but left-handers tend to prefer the one on their left (Casasanto, 2009). This pattern persists even when people make judgments orally, without using their hands to respond. Children as young as 5 years old already make evaluations according to handedness and spatial location, judging animals shown on their dominant side to be nicer and smarter than animals on their nondominant side (Casasanto \& Henetz, 2011).

Beyond the laboratory, the association of "good" with the dominant side can be seen in left- and right-handers' spontaneous speech and gestures. In the final debates of the 2004 and 2008 U.S. presidential elections, positive speech was more strongly associated with right-hand gestures and negative speech with left-hand gestures in the two right-handed candidates (Bush, Kerry), but the opposite association was found in the two left-handed candidates (McCain, Obama; Casasanto \&
Jasmin, 2010; Fig. 2). Body-specific associations between space and valence have visible consequences for the ways people communicate about positive and negative ideas.

\section{How using your hands can change your mind}

Why do right- and left-handers think differently in this way? These results cannot be predicted or explained by conventions in language and culture, which consistently associate "good" with "right" and "bad" with "left." Instead, implicit associations linking valence with left-right space appear to be created as people interact with their physical environment. In general, greater motor fluency leads to more positive feelings and evaluations: People like things better when they are easier to perceive and interact with (e.g., Ping, Dhillon, \& Beilock, 2009). Bodies are lopsided. Most of us have a dominant side and a nondominant side and therefore interact with the physical environment more fluently on one side of space than on the other. As a consequence, right-handers, who interact with their environment more fluently on the right and more clumsily on the left, come to implicitly associate "good" with "right" and "bad" with "left," whereas left-handers form the opposite association (Casasanto, 2009).

To test this proposal, Evangelia Chrysikou and I studied how people think about "good" and "bad" after their dominant hand has been handicapped, either due to brain injury or to something much less extreme: wearing a bulky ski glove. One experiment tested space-valence mappings in stroke patients a

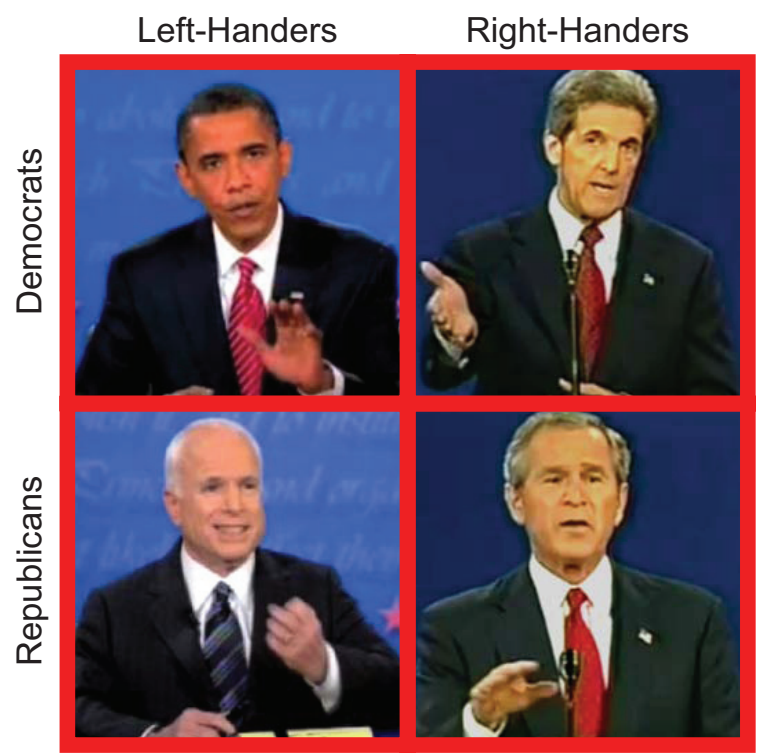

b

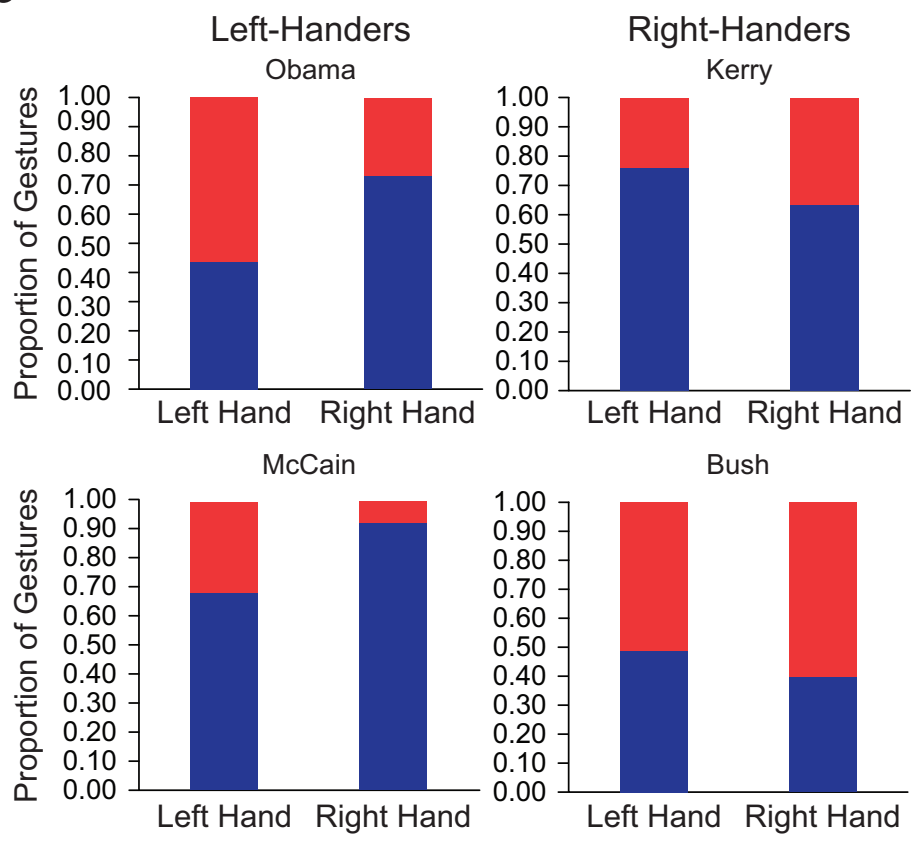

Fig. 2. Examples of dominant-hand gestures produced by the 2004 and 2008 U.S. presidential candidates during speech with positive emotional valence (left panels) and associations between speech and gesture in each presidential candidate (right panels). In the left-handers (Obama, McCain), left-hand gestures were more strongly associated with positive-valence speech (red bars) than were right-hand gestures, and right-hand gestures were more strongly associated with negative-valence speech (blue bars) than were left-hand gestures. The opposite association between hand and valence was found in the right-handers (Kerry, Bush). (Figure reproduced from Casasanto \& Jasmin, 20I0.) 
with hemiparesis (weakness or paralysis) on either their right or left side following damage to the opposite hemisphere of the brain. The patients, who had all been right-handed prior to brain injury, performed a task known to reveal body-specific space-valence associations in healthy participants. Patients who lost the use of their left hand after a stroke showed the usual right-is-good pattern. By contrast, patients who had lost the use of their right hand associated "good" with "left," like natural left-handers.

A similar reversal was found in healthy university students who performed a motor-fluency task while wearing a cumbersome glove on either their left hand (which preserved their natural right-handedness) or on their right hand, which turned them temporarily into left-handers. After about 12 minutes of lopsided motor experience, participants removed the glove and performed a test of space-valence associations, which they believed to be unrelated. Participants who had worn the left glove still thought "right" was "good," but participants who had worn the right glove showed the opposite left-is-good bias, like natural lefties (Casasanto \& Chrysikou, 2011).

Motor experience plays a causal role in shaping abstract thoughts. Even a few minutes of acting more fluently with the left hand can change right-handers' implicit associations between space and emotional valence, causing a reversal of their usual judgments. People generally have the impression that their judgments are rational and their concepts are stable. But if wearing a glove for a few minutes can reverse our usual decisions about good and bad, the mind may be more malleable than we thought.

The effects of short-term motor asymmetries are presumably temporary, but the same associative-learning mechanisms that changed people's judgments in the motor-training task may result in the long-term changes we found in stroke patients and may shape natural right- and left-handers' space-valence associations in the course of ordinary motor experience. Using our asymmetrical bodies, and therefore interacting with the physical environment more fluently on one side of space than the other, may serve as a kind of natural "motor training."

\section{Motivation and motor action}

Body-specific patterns of motor action lead to different emotion-related behaviors. Do they also lead to different neural organization for emotion? In right-handers, the left frontal lobe (which controls the dominant hand) is specialized for approach-motivational states, and the right frontal lobe (which controls the nondominant hand) is specialized for avoidancemotivational states (Davidson, 1992; Kinsbourne, 1978). This may be no mere coincidence. Perhaps brain areas that support approach and avoidance motivational states are functionally related to areas that support approach-related motor actions (which are often performed with the dominant hand) and avoidance-related actions (which are often performed with the nondominant hand). If so, hemispheric specialization for motivation should covary with hemispheric specialization for motor control and should therefore reverse between right- and left-handers (Casasanto, 2009).

To test this prediction, Geoffrey Brookshire and I used electroencephalography (EEG) to measure power in the alphafrequency band in right- and left-handers' brains. Across many studies, approach-motivational tendencies have been found to correlate with a reduction in alpha power (indicating more neural activity) in the left hemisphere compared to the right hemisphere for right-handers (Coan \& Allen, 2003). We observed this well-established pattern in right-handers, but we found the opposite pattern in left-handers (Brookshire \& Casasanto, 2011; Fig. 3). These results provide initial support for the functional link we proposed between the neural substrates of affective motivation and of motor control for manual actions. Emotional motivation is differently lateralized in right- and left-handers' brains, consistent with (and perhaps because of) handedness-related differences in hemispheric specialization for manual motor control.

\section{Conclusions and Future Directions}

People with different kinds of bodies think differently, in predictable ways. Even highly abstract thoughts depend, in part, on the ways people interact with the physical environment using their particular bodies. The body shapes the mind on various timescales. To the extent that habits of body-world interaction are stable, the habits of mental representation that
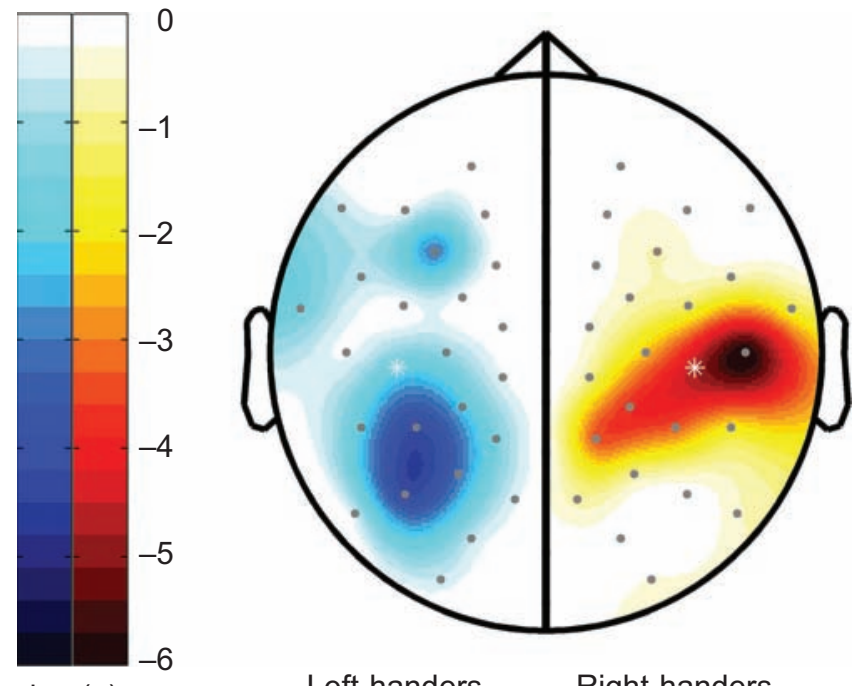

$\log (p)$

\section{Right-handers}

Fig. 3. Statistical significance of the interaction of handedness and approach motivational tendencies (both measured continuously) as predictors of power in the alpha-frequency band during resting-state EEG. Values of $p$ were computed independently at each homologous electrode pair, and $\log _{10}(p)$ was plotted separately in left-handers (left) and right-handers (right), with dark areas denoting higher statistical significance. In right-handers, high approach motivational tendencies predicted less alpha power (and therefore more neural activity) in the left hemisphere. In left-handers, the pattern was reversed: Approach-motivational tendencies predicted more neural activity in the right hemisphere. (Figure reproduced from Brookshire \& Casasanto, 20 I I.) 
they encourage should be stable over time; to the extent that they change, mental representations may change accordingly. Many other contextual factors influence the representations people form and the judgments they make as well, and other factors may override body-specific influences at times. But the body is an ever-present part of the context in which we use our minds and, therefore, has pervasive influences on the neurocognitive activity that constitutes our thoughts.

These first tests of the body-specificity hypothesis focused on how handedness, genetic or induced, influences thinking. On the basis of this bodily attribute, right- and left-handers tend to form systematically different mental images, create different word meanings, and arrive at opposite judgments about the same objects in the world. But there may be nothing special about the mechanisms by which the hands shape the brain and mind (e.g., associative learning), and body-specificity effects should extend beyond the initial test bed of handedness. The ways in which cognitive scientists could discover that bodily differences lead to cognitive differences are limited only by our imaginations.

Like research on linguistic relativity and cultural relativity, investigations of bodily relativity elucidate how patterns of experience give rise to corresponding habits of thinking, feeling, communicating, and making decisions. A further challenge is to determine how influences of linguistic, cultural, and bodily experiences combine to shape our mental lives.

\section{Recommended Reading}

Barsalou, L. (1999). Perceptual symbol systems. Behavioral and Brain Sciences, 22, 577-609. An influential proposal about the relationship between perceptuo-motor experiences and concepts.

Casasanto, D. (2009). (See References). A paper containing the proposal and first tests of the body-specificity hypothesis.

Ping, R.M., Dhillon, S., \& Beilock, S.L. (2009). (See References).

A review of research linking motor action with preference judgments.

Pulvermuller, F. (2005). Brain mechanisms linking language and action. Nature Reviews Neuroscience, 6, 576-582. A review of research linking action verb understanding with the motor system.

Wittgenstein, L. (1953). Philosophical investigations. In G.E.M. Anscombe \& R. Rhees (Eds.), G.E.M. Anscombe (trans.). Oxford: Blackwell. Philosophical foundations of the views proposed here on the context dependence of mental representations.

\section{Declaration of Conflicting Interests}

The author(s) declared no potential conflicts of interest with respect to the research, authorship, and/or publication of this article.

\section{Funding}

Research supported in part by an NRSA fellowship (\#F32 MH072502), the Max Planck Gesellschaft, a grant from the Consejeria de Innovacion, Ciencia y Empresa, Junta de Andalucia, and the European Regional Development Fund (Project P09SEJ-4772), and a James S. McDonnell Foundation Scholar Award.

\section{References}

Barsalou, L.W. (1987). The instability of graded structure: Implications for the nature of concepts. In U. Neisser (Ed.), Concepts and conceptual development: Ecological and intellectual factors in categorization (pp. 101-140). Cambridge, UK: Cambridge University Press.

Brookshire, G., \& Casasanto, D. (2011). Motivation and motor control: Hemispheric specialization for motivation reverses with handedness. In L. Carlson, C. Hölscher, \& T. Shipley (Eds.), Proceedings of the 33rd Annual Conference of the Cognitive Science Society (pp. 2610-2615). Austin, TX: Cognitive Science Society.

Casasanto, D. (2009). Embodiment of abstract concepts: Good and bad in right- and left-handers. Journal of Experimental Psychology: General, 138, 351-367.

Casasanto, D., \& Chrysikou, E.G. (2011). When left is "right": Motor fluency shapes abstract concepts. Psychological Science, 22, 419-422.

Casasanto, D., \& Henetz, T. (2011). Handedness shapes children's abstract concepts. Cognitive Science [e-pub before print]. DOI: 10.1111/j.1551-6709.2011.01199

Casasanto, D., \& Jasmin, K. (2010). Good and bad in the hands of politicians. PLoS ONE, 5(7), e11805. doi:10.1371/journal .pone.0011805

Casasanto, D., \& Lupyan, G. (2011). Ad hoc cognition. In L. Carlson, C. Hölscher, \& T. Shipley (Eds.), Proceedings of the 33rd Annual Conference of the Cognitive Science Society (p. 826). Austin, TX: Cognitive Science Society.

Chomsky, N. (1965). Aspects of the theory of syntax. Cambridge, MA: MIT Press.

Coan, J.A., \& Allen, J.J.B. (2003). Frontal EEG asymmetry and the behavioral activation and inhibition systems. Psychophysiology, 40, 106-114.

Davidson, R.J. (1992). Anterior cerebral asymmetry and the nature of emotion. Brain and Cognition, 20, 125-151.

Fischer, M.H. (2005). Perceived reachability: The roles of handedness and hemifield. Experimental Brain Research, 160, 283-289.

Fodor, J.A. (1998). Concepts: Where cognitive science went wrong. Oxford, UK: Oxford University Press.

Kinsbourne, M. (1978). The biological determinants of functional bisymmetry and asymmetry. In M. Kinsbourne (Ed.), Asymmetrical function of the brain. New York, NY: Cambridge University Press.

Linkenauger, S.A., Witt, J.K., Stefanucci, J.K., Bakdash, J.Z., \& Proffitt, D.R. (2009). The effect of handedness and reachability on perceived distance. Journal of Experimental Psychology: Human Perception and Performance, 35, 1649-1660.

Machery, E. (2009). Doing without concepts. New York, NY: Oxford University Press.

Ping, R.M., Dhillon, S., \& Beilock, S.L. (2009). Reach for what you like: The body's role in shaping preferences. Emotion Review, 1, $140-150$.

Plato. (2010). Phaedo. Project Gutenberg. Retrieved from http:// www.gutenberg.org/ebooks/1658

Prinz, J. (2002). Furnishing the mind. Cambridge, MA: MIT Press. 
Willems, R.M., Hagoort, P., \& Casasanto, D. (2010). Body-specific representations of action verbs: Neural evidence from right- and left-handers. Psychological Science, 21, 67-74.

Willems, R.M., Labruna, L., D’Esposito, M., Ivry, R., \& Casasanto, D. (2011). A functional role for the motor system in language understanding: Evidence from theta-burst transcranial magnetic stimulation. Psychological Science, 22, 849-854.
Willems, R.M., Toni, I., Hagoort, P., \& Casasanto, D. (2009). Bodyspecific motor imagery of hand actions: Neural evidence from right- and left-handers. Frontiers in Human Neuroscience, 3(39), $1-9$.

Willems, R.M., Toni, I., Hagoort, P., \& Casasanto, D. (2010). Neural dissociations between action verb understanding and motor imagery. Journal of Cognitive Neuroscience, 22, 2387-2400. 